\title{
The Influence of Austenite Grain Size during Welding Simulations of Ferritic Steels
}

\author{
Cory $\mathrm{J}_{\text {Hamelin }}{ }^{1, \mathrm{a}}{ }^{*}$, Ondrej Muránsky ${ }^{1, \mathrm{~b}}$, Lyndon Edwards ${ }^{1, \mathrm{c}}$ \\ ${ }^{1}$ Australian Nuclear Science and Technology Organisation, Lucas Heights NSW 2232, Australia \\ a cory.hamelin@ansto.gov.au, bondrej.muransky@ansto.gov.au, ${ }^{\mathrm{C}}$ lyndon.edwards@ansto.gov.au
}

Keywords: welding; finite element method; ferritic steel; phase transformation; grain size

\begin{abstract}
In recent years, considerable progress has been made in the simulation of ferritic steel welding processes. The successful residual stress validation of a single-pass autogenous TIG beam weld in SA508 Gr.3 Cl.1 steel has identified key simulation variables required for the accurate prediction of post-weld residual stress in ferritic weldments. The present work outlines a sensitivity study performed to examine the influence of austenite grain growth on predicted solid-state phase transformation kinetics and consequently, residual stress predictions.
\end{abstract}

\section{Introduction}

Previous studies have highlighted the importance of solid-state phase transformation (SSPT) kinetics in the analysis of ferritic steel weld models [1-3]. The total strain is influenced by a reversible volumetric strain $\left(\varepsilon^{t r}\right)$ due to changes in crystal structure during SSPT, and also by a finite irreversible transformation strain $\left(\varepsilon^{t p}\right)$. Two mechanisms have been identified that contribute to $\varepsilon^{t p}$ : (i) the rapid volumetric change during SSPT creates localized micro-plasticity in the weaker phase via local lattice mismatch, leading to directional plastic flow under a deviatoric stress state [4]; and (ii) variant selection during displacive phase transformations, first attributed to the work of Magee [5], who postulated the formation of martensite plates on preferred crystallographic planes under a deviatoric stress state to minimize the internal energy.

Oddy et al. [1] have shown the significance of transformation strain on the final predicted residual stress field in single-pass repair welds. The mechanisms for generating $\varepsilon^{t p}$ have been found to be dependent on both the deviatoric stress state present during SSPT, as well as the transformation rate [6]. Therefore, accurate predictions of SSPT kinetics are required to account for both of these variables. An important characteristic that directly affects SSPT kinetics is austenite grain growth; Coon and Watt [12] have shown that the predicted austenite grain size can have a profound impact on the heat affected zone (HAZ) microstructure. It follows that such an effect would subsequently alter the predicted residual stress field. The present study is therefore an extension of the observations of Coon and Watt, to examine the extent that predictions of austenite grain size will influence the predicted weld residual stress field.

\section{SSPT Finite Element Model}

Several recent numerical weld analyses involving ferritic steel have incorporated a phase transformation algorithm to capture local variations in SSPT kinetics [7-9]. These models use the semi-empirical equations generated by $\mathrm{Li}$ et al. [10] to capture the isothermal transformation kinetics in ferritic steels. In these equations, the austenite decomposition to ferrite, pearlite and/or bainite is determined as a function of both the chemical composition of the steel and the austenite grain size $(G)$ :

$$
\tau(X, T)=\frac{F(\mathrm{C}, \mathrm{Mn}, \mathrm{Si}, \mathrm{Ni}, \mathrm{Cr}, \mathrm{Mo}, G)}{\Delta T^{n} \exp (-Q / R T)} S(X)
$$

where the time $\tau$ required for a given transformation to reach a fraction of completion $X$ at constant temperature $T$ (in $\mathrm{K}$ ) is calculated; $\Delta T$ is the amount of undercooling; $Q$ is the activation energy for 
the diffusion reaction; $R$ is the gas constant; $n$ is an empirical constant based on the effective diffusion mechanism; and $S(X)$ is a sigmoidal function defining the reaction rate. Integration of Eq. 1 into a finite element heat transfer model has been shown to accurately predict the post-weld microstructure present in the fusion and heat-affected zones of a ferritic steel weldment [9,11]. Using the austenite decomposition predicted by the SSPT algorithm allows for accurate prediction of the volumetric strain associated with phase change $\left(\varepsilon^{t r}\right)$. To capture the irreversible transformation-induced strain $\left(\varepsilon^{t p}\right)$, an equation developed by Leblond et al. [6] is used:

$$
\dot{\varepsilon}_{i j}^{t p}=\frac{3}{2} K s_{i j} f^{\prime}(z) \dot{z}
$$

where $s_{i j}$ is the deviatoric stress tensor; $z$ is the volume fraction of the phase being formed; $K$ is a material constant, found by Leblond et al. to be $\cong 10^{-4} \mathrm{MPa}^{-1}$ for SA508 Gr.3 steels; and $f(z)$ is a normalized function of the proportion of the phase formed.

To illustrate the sensitivity of residual stress predictions to austenite grain growth, two sets of numerical analyses are performed. The analyses are both sequentially-coupled thermo-mechanical finite element analyses, using the ABAQUS commercial software package. In the first set of analyses, the austenite grain size is predicted using the approach of Ikawa et al. [16]. The steel is assumed to have an initial equi-axed austenite grain size (upon austenisation) of $0.015 \mathrm{~mm}$, which will increase at temperatures above $1000^{\circ} \mathrm{C}$ at a rate defined by:

$$
D^{a}-D_{0}^{a}=k_{0} \operatorname{texp}(Q / R T)
$$

where $D$ and $D_{0}$ are the final and initial grain size, respectively; $t$ is the time interval at the elevated temperature $T ; a$ and $k_{0}$ are material constants (equal to 4 and $2.969 \times 10^{15} \mathrm{~mm}^{4} / \mathrm{min}$, respectively); and $Q$ is the activation energy for grain growth $\left(1.269 \times 10^{5} \mathrm{cal} / \mathrm{g}\right.$-atom $)$. Larger grain sizes within the fusion zone are predicted using Eq. 4 with an upper bound on $T$ equal to the assumed melting temperature, $1450{ }^{\circ} \mathrm{C}$. In the second set of analyses, a constant grain size of $15 \mu \mathrm{m}$ was used; this value was chosen as Ikawa et al. have observed an average initial austenite grain size of between $13-20 \mu \mathrm{m}$ for a range of ferritic steels [16].

\section{Weld Specimen}

The simulation objects used for model validation are two sets of edge-welded beam specimens produced under Task Group 5 of the European NeT programme [13]. The welds are single-pass autogenous TIG welds in SA508 Gr.3 Cl.1 ferritic steel. The two weldment sets differ in terms of the torch power, torch speed, and sample pre-heat conditions. A full description of the welding conditions, and the subsequent weld residual stress measurements, has been provided by Smith et al. [14]. The weldments produced using a higher torch speed (TG5-F) have run-on and run-off plates attached as shown in Fig. 1, to achieve steady-state weld conditions at the beam mid-length. These plates are not required in the slower torch speed welds (TG5-S).

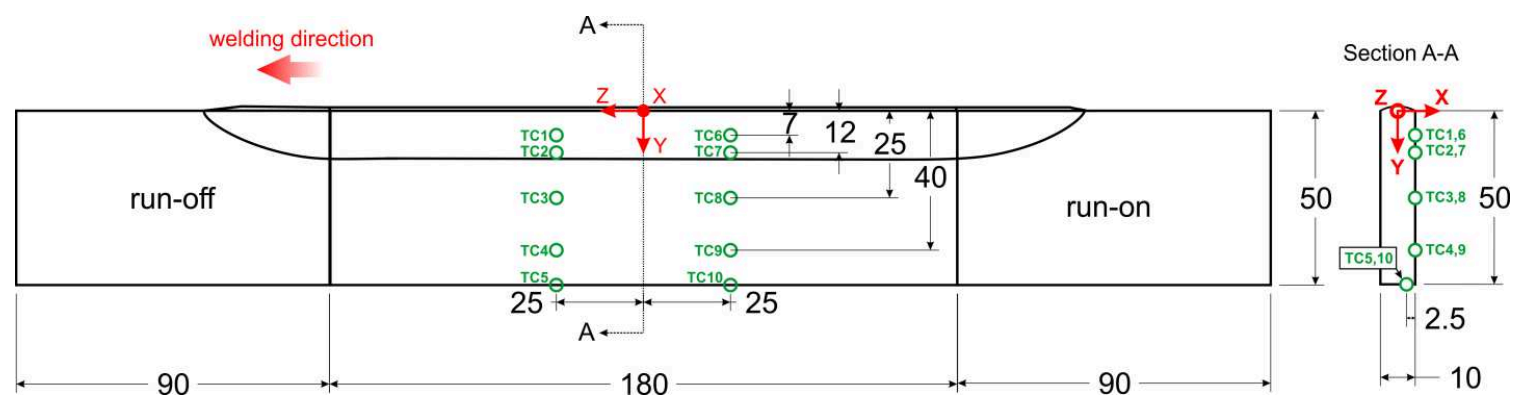

Figure 1. A representative sample produced for NeT Task Group 5 (all dimensions in $\mathrm{mm}$ ). The beam thickness is $10 \mathrm{~mm}$. Nominal thermocouple locations are shown (TC1-TC10). 


\section{Results}

The microstructural predictions of the ABAQUS SSPT subroutine [9] were validated against both TG5-F and TG5-S weld specimens, by comparing predicted phase-dependent hardness profiles with cross-weld micro-hardness measurements taken at the mid-length of each sample. The predicted hardness was calculated using equations developed by Maynier et al. [15]. Validation of the predicted microstructure for both weldments is shown in Fig. 2 and Fig. 3 for TG5-F and TG5-S specimens, respectively. The predicted cross-weld residual stress profiles for both TG5-F and TG5$\mathrm{S}$ are also presented in Fig. 2 and Fig. 3, respectively, alongside neutron diffraction and synchrotron $\mathrm{X}$-ray measurements from Smith et al. [14].

Good agreement between the measured and predicted residual stress profiles is observed for the TG5-F sample (Fig. 2) irrespective of the analysis used (i.e. with or without grain growth), although the predicted phase distributions with and without grain growth are considerably different. The insensitivity of residual stress predictions to delays in austenite decomposition based on grain size for the TG5-F sample shows that when the cooling rate is sufficiently high, it becomes the primary factor influencing the transformation strain and consequently the residual stress state. When considering the predicted phase-dependent hardness, it is clear that the model that accounts for grain growth more accurately captures the measured phase distribution in the sample, which is predominantly martensitic in the fusion zone $(\mathrm{Y}<3.5 \mathrm{~mm})$ with increasing amounts of bainite towards the HAZ $(3.5<\mathrm{Y}<6 \mathrm{~mm})$.

In contrast to the TG5-F analyses, the TG5-S analyses (Fig. 3) show no variation of the predicted post-weld phase distribution, which is almost entirely bainitic. However, while the final predicted phase distribution is unaffected, the overall SSPT kinetics are markedly different as evidenced by the residual stress predictions. The SSPT kinetics are therefore increasingly important for accurate residual stress predictions as the cooling rate in the weld region decreases. Unlike the TG5-F analyses, the normal stress profiles in the TG5-S analyses show an increase in model accuracy when no grain growth is considered. This result suggests the austenite grain size is being over-predicted by Eq. 3, leading to an overestimate of the time required for bainite nucleation and growth. The delay in transformation leads to an increase in transformation plasticity, as internal deviatoric stresses accumulate due to thermal mismatch during cooling. The variation in $\varepsilon^{t p}$ leads to a notable variation in the final residual stress field, as shown in Fig. 3. Recent studies from Pous-Romero et al. [17] indicate improvements to the accuracy of grain growth models are achievable, which would lead to an increase in the overall numerical accuracy of FEA for phase and residual stress predictions.

Finally, the variation in stress predictions shown in Fig. 3 are confined to the weld fusion zone and HAZ, indicating the SSPT kinetics (as influenced by the austenite grain size) will only affect this region. However, both TG5-S models predict a longitudinal bending stress in the parent metal $(12<\mathrm{Y}<50 \mathrm{~mm})$, which is not measured via both neutron and synchrotron $\mathrm{X}$-ray diffraction techniques. It can be shown that the longitudinal bending stress predictions can be improved through adjustment of the austenisation temperatures $\left(A_{c 1}\right.$ and $\left.A_{c 3}\right)$ used in the SSPT algorithm; however, this work lies outside the scope of the present study.

\section{Summary}

A series of numerical weld simulations have been conducted based on two sets of edge-welded beams produced using SA508 Gr.3 Cl.1 ferritic steel. The numerical analyses indicate that the higher cooling rates observed in the weld region of the TG5-F sample is the key simulation parameter required for accurate residual stress predictions, while austenite grain size must only be considered for accurate predictions of the post-weld phase distribution. In contrast, the slower cooling rates observed in the TG5-S sample causes residual stress predictions to become increasingly sensitive to phase transformation kinetics, which are directly influenced by austenite grain size predictions. 

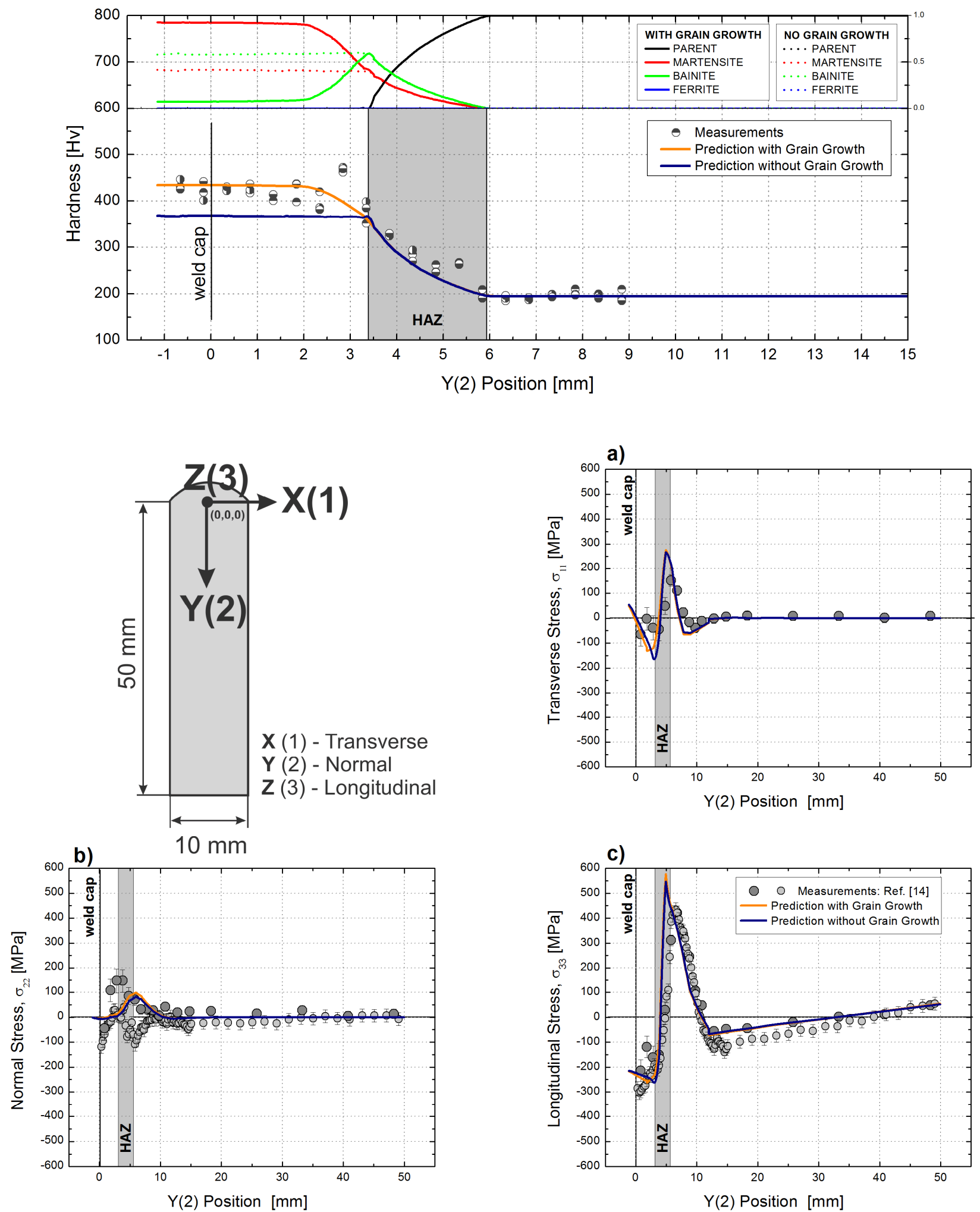

Figure 2. Measured cross-weld micro-hardness profiles (above) and residual stress profiles (below) for the TG5-F sample vs. model predictions that account for grain growth, and model predictions that assume a constant grain size. 

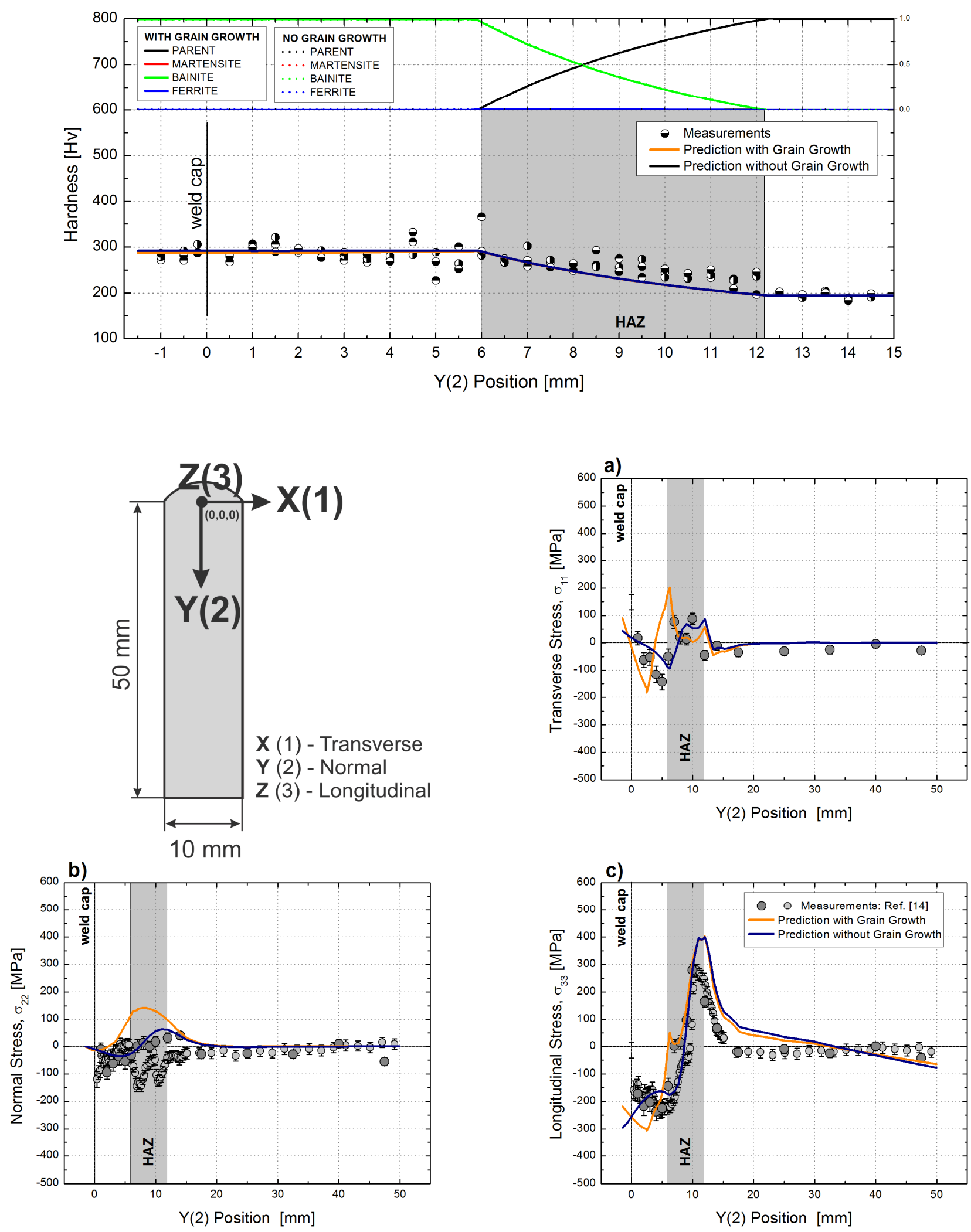

Figure 3. Measured cross-weld micro-hardness profiles (above) and residual stress profiles (below) for the TG5-S sample vs. model predictions that account for grain growth, and model predictions that assume a constant grain size. 


\section{References}

[1] A.S. Oddy, J.A. Goldak, J.M.J. McDill, Transformation plasticity and residual stresses in singlepass repair welds, J. Press. Vess.-T. ASME, 114 (1992) 33-38.

[2] J.A. Francis, H.K.D.H. Bhadeshia, P.J. Withers, Welding residual stresses in ferritic power plant steels. Mater. Sci. Tech., 23 (2007) 1009-1020.

[3] D. Deng, H. Murakawa, Influence of transformation induced plasticity on simulated results of welding residual stress in low temperature transformation steel. Comp. Mater. Sci. 78 (2013) 55-62.

[4] G.W. Greenwood, R.H. Johnson, The deformation of metals under small stresses during phase transformations, P. R. Soc. A., 283 (1965) 403-422.

[5] C.L. Magee, Ph.D. thesis, Carnegie-Mellon University, 1966.

[6] J.-B. Leblond, G. Mottet, J. Devaux, J.-C. Devaux, Mathematical models of anisothermal phase transformations in steels, and predicted plastic behaviour, Mater. Sci. Tech., 1 (1985) 815-822.

[7] H. Dai, J.A. Francis, P.J. Withers, Prediction of residual stress distributions for single weld beads deposited on to SA508 steel including phase transformation effects, Mater. Sci. Tech., 26 (2010) 940-949.

[8] J.-S. Kim, S.-H. Lee, T.-E. Jin, Fatigue evaluation of dissimilar welds on nuclear components, Transactions of SMiRT 17, paper D03-2, 2003.

[9] C.J. Hamelin, O. Muránsky, P.J. Bendeich, K. Short, L. Edwards, Predicting solid-state phase transformations during welding of ferritic steels, Mater. Sci. Forum, 706-709 (2012) 1403-1408.

[10] M.V. Li, D.V. Niebuhr, L.L. Meekisho, D.G. Atteridge, A computational model for the prediction of steel hardenability, Metall. Mater. Trans. B, 29 (1998) 661-672.

[11] C. Henwood, M. Bibby, J.A. Goldak, D. Watt, Coupled heat transfer - microstructure weld computations (Part B), Acta Metall. Mater., 36 (1988) 3037-3046.

[12] L. Coon, D.F. Watt, Simulation of weld HAZ microstructural development, in: J. Too (Ed.), Computer Modelling of Fabrication Processes and Constitutive Behaviour of Materials, CANMET, Ottawa (1987) 467-486.

[13] C. Ohms, R.V. Martins, O. Uca, A.G. Youtsos, P.J. Bouchard, M.C. Smith, M. Keavey, S.K. Bate, P. Gilles, R.C. Wimpory, L. Edwards, The European Network on Neutron Techniques Standardisation for Structural Integrity (NeT), Proc. ASME PVP Division Conf. (2008) 625-637.

[14] M.C. Smith, S.K. Bate, P.J. Bouchard, Simple benchmark problems for finite element weld residual stress simulation, Proc. ASME PVP Division Conf. (2013) paper PVP2013-98033.

[15] P. Maynier, J. Dollet, P. Bastien, Prediction of microstructure via empirical formulae based on CCT diagrams, in: D.V. Doane, J.S. Kirkaldy (Eds.), Hardenability Concepts with Applications to Steel, The Metallurgical Society of AIME (1978) 163-178.

[16] H. Ikawa, S. Shin, H. Oshige, Y. Mekuchi, Austenite grain growth of steels during thermal cycles, Trans. Jpn. Weld. Soc. 8 (1977) 46-51.

[17] H. Pous-Romero, I. Lonardelli, D. Cogswell, H.K.D.H. Bhadeshia, Austenite grain growth in a nuclear pressure vessel steel, Mat. Sci. Eng. A-Struct. 567 (2013) 72-79. 